\title{
The Legal Framework for Space Debris Remediation as a Tool for Sustainability in Outer Space
}

\author{
Rada Popova ${ }^{1, *}$ and Volker Schaus ${ }^{2}$ \\ 1 Institute of Air and Space Law, University of Cologne, 50923 Köln, Germany \\ 2 Institute of Space Systems, Technische Universität Carolo-Wilhemina zu Braunschweig, 38108 Braunschweig, \\ Germany; v.schaus@tu-braunschweig.de \\ * Correspondence: rada.popova@uni-koeln.de; Tel.: +49-221-470-4017
}

Received: 28 February 2018; Accepted: 2 May 2018; Published: 9 May 2018

\begin{abstract}
The growth of orbital space debris is both a consequence of and a potential hindrance to space activities. The risks posed by space debris propagation in the most used orbital regions highlight the need to adequately address the challenges posed to the sustainability in outer space. The preservation of the access to and usability of outer space in the long-term requires that action is taken which has to be the result of both mitigation and remediation measures for existing and future space missions. As the enforcement of such technical measures will depend on adequate regulation, they need to be approached also from a legal perspective. The deficiencies in law for space debris remediation mechanisms originate from the fact that although technical concepts have been developed, the legal framework for space activities does not impose any legal obligations for debris removal and on-orbit servicing. Nevertheless, an overview of the relevant legal framework shows that there is a legal basis for the protection of the outer space environment which can, as has already been the case with space debris mitigation guidelines, be substantiated in more concrete terms by the formulation of voluntary, non-binding instruments and included in national legislation.
\end{abstract}

Keywords: space debris; remediation; sustainability; space law; environmental protection; orbital propagation; reference models; space debris mitigation guidelines; active debris removal

\section{Introduction}

The importance of the sustainability of outer space as the sum of measures ensuring that the outer space environment is preserved for current and future generations has gained international recognition from a technical, legal and policy perspective. Given a backdrop of the risks posed to some of the most used orbital regions in near-Earth space by the growing amount of space debris, adequate consideration of instruments aiming at the mitigation and remediation of space debris represents an important tool to ensure the viability of space activities in the future. However, studies modelling the orbital evolution of space debris show that the application only of mitigation measures will not suffice to ensure the future access and usability of outer space [1]. Thus, space debris remediation (SDR) will play a crucial role for the sustainability of outer space and must become an integral part of the legal framework regulating its use.

While technical mitigation measures for future missions have acquired legal relevance by being included in instruments regulating space activities, space debris remediation models have not yet become part of the legal framework. The aim of this work is to provide an overview of the legal background relevant to SDR and to analyse the main legal challenges for the future regulation of SDR. By exploring the factual background to space debris, it will be shown that effective technical SDR mechanisms need to be defined also at the legal level and that, although the law is still far behind the technology, legal avenues exist to legal implement SDR. 


\section{Why Space Debris Remediation? The Facts}

\subsection{The Status of the Outer Space Environment}

In outer space, any launch creates space debris. Since the first man-made object was launched into space in 1957, more than 5600 launches have taken place [2]. In addition, incidents and collisions create additional space debris. As a result, human activities have caused significant negative effects on outer space, as during the past six decades near-Earth orbits have been filled with functional and non-functional objects, the overwhelming majority of which are debris.

Of course, this observation is not relevant for the whole of outer space. For the purposes of this article, and of space law in general, the subject of interest is naturally restricted to the orbital regions that are accessible for man-made spacecraft and are used for space activities. The farthest space mission so far-Voyager-I-has left the solar system and entered interstellar space. Nevertheless, most human activities take place in low-Earth orbit (LEO) in an altitude between 200 and $2000 \mathrm{~km}$ used for the International Space Station, Earth observation satellites as well as some telescopes, medium-Earth orbit (MEO) in an altitude approximately between 2000 and 36,000 km mostly used for navigation, geodetic and communication satellites as well as geostationary Earth orbit (GEO) at approximately $36,000 \mathrm{~km}$. Currently, there are 1738 functional satellites, of which 1071 are in LEO, 531 in GEO, 97 in MEO and 39 in elliptical orbits [3].

Currently, only $6 \%$ of the catalogued orbital population are functional objects. The number of non-functional objects that are trackable and contained in the Space Surveillance Network catalogue show that there are more than 21,000 larger than $10 \mathrm{~cm}$. For smaller sizes, the estimates are based on statistical models, such as the NASA Standard Breakup Model [4] and in-situ measurements. The estimates include 150 million objects larger than $1 \mathrm{~mm}$ and 600,000 objects up to $1 \mathrm{~cm}$. Moreover, 700,000 to 750,000 pieces of space debris larger than $1 \mathrm{~cm}$ have resulted from more than 200 on-orbit defragmentations [5].

As a consequence of the vast orbital velocity in LEO $(8 \mathrm{~km} / \mathrm{s}=28,800 \mathrm{~km} / \mathrm{h})$, impacts with the smallest objects of $1 \mathrm{~mm}$ might cause degradation and damage to functional spacecraft. So far, shielding options have been developed, but they are only effective for fragments not larger than $1 \mathrm{~cm}$. Impacts with larger objects have the potential to destroy functional satellites.

This is linked to the decisive factor for the constant growth in debris: the 'Kessler syndrome'-a cascade effect describing the fact that collisions between space debris result in an exponential growth in the orbital debris population which, once collisional break-up begins, will increase even if no new launches take place $[6,7]$.

In the near future, a further "growth factor" which might additionally influence space debris propagation are so-called 'mega-constellations' that will consist of hundreds of small satellites with a short operational lifetime and restricted manoeuvring capability [8-10]. Table 1 lists recently announced satellite constellations aiming to provide global internet communications which have attracted much publicity. Some commonalities include: (1) the orbital altitudes above the popular 800-900 km Sun-synchronous orbits where atmospheric drag is non-existent; and (2) the compact mass of objects below $500 \mathrm{~kg}$ which suggests low-thrust electrical propulsions for orbital manoeuvers. The list of announced constellations could easily be extended. However, it is unlikely that all announced plans turn into reality. In such global business scenarios, typically the first-in-the-market along with two or three competitors apportion the market among themselves. This happened in the 1990s, when several global communication LEO constellation systems were announced of which only Iridium, Globalstar and Orbcomm made it into orbit. Keeping in mind that approximately 1000 active satellites are in LEO today, with the announced OneWeb mega-constellation this number will almost double [11], and if all three constellations on the list are launched, this would result in a tenfold increase in the LEO satellite population. 
Table 1. Selection of recently proposed large satellite constellations; based on [12].

\begin{tabular}{cccccl}
\hline Company & No. Satellites & Orbit & Mass/kg & Frequencies & \multicolumn{1}{c}{ Remarks } \\
\hline OneWeb & 900 & $\begin{array}{c}1200 \mathrm{~km}, 18 \\
\text { polar planes }\end{array}$ & $175-200$ & $\mathrm{~K}_{\mathrm{u}}$-Band & $\begin{array}{l}\text { First to register the frequencies at the Federal } \\
\text { Communications Commission (FCC) }\end{array}$ \\
\hline $\begin{array}{c}\text { Starlink } \\
\text { (SpaceX) }\end{array}$ & 4425 & $\begin{array}{c}1100-1325 \mathrm{~km}, \\
83 \text { planes, } \\
53-81^{\circ} \text { incl. }\end{array}$ & $100-500$ & $\mathrm{~K}_{\mathrm{u}} / \mathrm{K}_{\mathrm{a}}$ & $\begin{array}{l}\text { First 2 demo satellites in orbit (launched 22 } \\
\text { February 2018); optical inter-satellite link }\end{array}$ \\
\hline Boeing & 2956 & $1200 \mathrm{~km}$ & - & V-Band & - \\
\hline
\end{tabular}

The scope of challenges posed by orbital debris pollution is further underlined by the restricted cataloguing possibilities and the relative effectiveness of space situational awareness systems. The catalogue maintained by the US Space Surveillance Network provides information on 16,000 objects [13]. The Space Awareness System of the European Space Agency (ESA) can track objects bigger than $10 \mathrm{~cm}$ in low-Earth orbits and $0.3-1 \mathrm{~m}$ in geostationary orbits [14]. Thus, only a small fraction of the overall debris population can be detected. Furthermore, even if a collision probability can be calculated, manoeuvring may not be feasible, e.g., due to restricted time for reaction or lack of manoeuvring capabilities or control over the satellite. Unlike the environment of the Earth that might be cleaned-up and restored to a previous state, outer space is governed by celestial mechanics which make it practically impossible to clean-up debris through natural orbital decay and thereby bring the orbital environment to its original state.

The natural decay of space debris is dominated by the drag caused by the residual atmosphere. The effect is dependent on the mass, the cross-sectional area, and the orbital position of the space object. Space debris at $800 \mathrm{~km}$ may remain in orbit for the next few centuries [15] and space debris orbiting at more than $1500 \mathrm{~km}$ will practically remain in outer space forever as there is not enough drag from Earth's atmosphere any more at this altitude [16].

All of these factors make for an alarming picture. In general, one can distinguish between collisions (in which two objects are involved) and break-up events (which can occur if a satellite is breaking up by itself because of residual fuel in the tanks or a self-destruct mechanism). Although so far only a few on-orbit collisions have occurred [17] (e.g., the 2007 anti-satellite missile test conducted by China on its Feng-Yun 1C satellite and the 2009 collision between the inactive Russian satellite Cosmos 2251 and the active US satellite Iridium 33), a dramatic growth in the space debris population has been caused by these accidents. Alone the 2009 collision led to the creation of a space debris cloud of 2000 pieces of debris larger than $10 \mathrm{~cm}$ and thousands of smaller pieces which might remain in orbit for years [18].

The number of collisions that will lead to further incidents will grow over time. This risk is particularly high for near-polar LEO orbits at around 800-900 km and the GEO region, as approximately $62 \%$ of functional satellites are in LEO and $31 \%$ in GEO [3,19]. As LEO is the region of greatest concern for the uncontrolled growth of debris, currently, the following mechanisms are considered vital to mitigate the debris population to a sustainable level: (1) post-mission disposal; (2) passivation; and, (3) active debris removal. While a few years ago, less than $50 \%$ of the missions in GEO were compliant with space debris mitigation standards [20], in 2016, more than $80 \%$ successful clearance attempts were undertaken in GEO and 66\% in LEO [21].

It has been estimated that compliance with mitigation rules, e.g., through ensuring that $90 \%$ of the launches are in compliance with the 25-year rule of post-mission disposal as provided by the Space Debris Mitigation Guidelines of the Inter-Agency Space Debris Coordination Committee (IADC) [22] and no new on-orbit explosions occur, will not be enough to reverse the negative trend in the most used orbits. These findings were studied in detail by the IADC in simulation campaigns among the participating partners, and recently confirmed by reference simulation in the frame of the H2020-ReDSHIFT project [23]. Furthermore, even if up to 10 large objects are removed from low-Earth orbit per year, the debris growth in LEO is still likely to evolve negatively in the next 200 years [1]. 
Long-term reference scenarios conducted recently within the H2020-ReDSHIFT project used a space debris population from LEO to GEO and a projection time frame of 200 years. Assuming 2-3 self-induced in-orbit explosions over the next 15 years, a post-mission disposal success rate of $60 \%$ (on 25-year orbits in LEO and to graveyard orbits in GEO) and collision avoidance against all objects in LEO, the results show that remediation of two objects per year decreases $12 \%$ of the final population [24].

Thus, it is expected that a combination of mitigation and remediation measures is needed to overcome the negative trends which will, with time, evolve into a catastrophic state if no effective action is undertaken.

While an established (voluntary) framework for non-binding mitigation measures and some state practice exists through the adoption of specific measures for space debris mitigation in the national space laws of some states [25], the legal implementation of space debris remediation (SDR) is still in the making. The reasons for the slow pace of this development are, on the one hand, of a technological nature and, on the other, are due to the complex legal problems posed by SDR. In the following sub-section, an overview of the legal framework and the main challenges for establishing rules on SDR will be given.

\subsection{The Legal Framework for Space Activities}

The legal framework for outer space activities consists of five international treaties (the 1967 Outer Space Treaty (OST) [26], the 1968 Rescue Agreement [27], the 1972 Liability Convention [28], the 1975 Registration Convention [29], and the 1979 Moon Agreement [30]) adopted in the period between 1967 and 1979, resolutions of the General Assembly of the United Nations adopted since 1982, and the national space legislation of more than 20 countries. Since 1996, a tendency can be observed to adopt sets of measures and instruments on the international level that re-interpret concepts entailed in earlier Treaties [31].

The Outer Space Treaty is sometimes referred to as a "Constitution" of space law as it contains the basic principles for space activities, provides the basis for the next four treaties, and has gained significant support, with 107 signatories as of January 2018 [32]. Thereby the Outer Space Treaty is considered to contain principles of customary international law, which bind not only state parties to the treaty but also non-signatories [33]. Such customary principles are Articles I-IV, VI, VII, VIII and arguably also Art. IX OST and have served as a basis for the development of the further treaties on space law.

International law designates outer space and celestial bodies the status of a global common-a domain beyond national jurisdiction which is not subject to national sovereignty. This is laid down in Art. I para. 1 of the 1967 Outer Space Treaty [26], according to which the use and exploration and use of outer space should be regarded as the 'province of all mankind'. While it is difficult to define this notion in concrete terms, there is no doubt that outer space should be open to the use of all states, regardless of their current economic or technological development [34].

Thus, the use of outer space as a global common, including economic and non-economic uses as well as scientific exploration of outer space and celestial bodies, should be free-in the sense of remaining accessible for all states and their nationals on the same terms, without discrimination of any kind. Accessibility as a means to carry out space activities should be preserved not only in the short-term perspective, but on a long-term basis as the dependency of humans on outer space will only grow in the future. As a consequence, the sustainability of space activities must be ensured.

It is, therefore, worthwhile discussing whether, if such activities are endangered by the negative consequences of orbital pollution, the rights of states to freely exercise their activities in outer space as stipulated in the Outer Space Treaty can be safeguarded. 
- The Freedoms vs. the Usability of Outer Space

The principles contained in the Outer Space Treaty and the subsequent four treaties on space law set out a framework for human activities in space that can be characterized as a system of freedoms and limitations. Art. I of the OST provides that there shall be freedom of the exploration, use and scientific investigation of outer space and celestial bodies. "Use" means both the economic and non-economic use of outer space [35]. The term "exploration", however, stipulates not so much consuming or profiting from space but rather the discovery of something new or yet unknown. Scientific investigation might but must not necessarily overlap with "exploration" as scientific activities might be aimed also at already discovered objects or areas.

The term "freedom" means that all addressees of these provisions (primarily states and also nationals of states, in as much as states entitle them to do so through national space legislation) are entitled to use, explore or scientifically investigate outer space without the need to ask for permission from other states or an international entity. At the same time, this means that such activities shall not be hampered, e.g., by harmful interference or other impairment.

However, the freedoms of outer space are not absolute, as they are not limitless. Limitations are certain exceptions contained in Article I of the OST itself as well as in other treaty provisions of the corpus iuris spatialis. Such as, inter alia, the common benefit clause (Art. I para 1 OST), Art. III OST and Article 2 UN Charter, Art. IV para 1 OST, Art. VII OST and Art. 2 and 3 Liability Convention.

Some of these limitations are specifically relevant for the sustainable use and exploration of outer space and celestial bodies, and thus for SDR, as sustainability is an indispensable condition for the usability of outer space. It is thereby required that the use of outer space by present generations takes place on the basis of responsibility towards future generations, which is reiterated by the specific nature of outer space as a global common.

- The notion of the "province of mankind"

In Art I para 1 of the OST and Art. 4 of the Moon Agreement the use and exploration of space and celestial bodies are declared to be the "province of mankind". Although no definition of the term "mankind" has been provided, this notion is an expression of the equal right of all states (regardless of the fact that they are space-faring or developing countries) and all generations (present and future) in the use and exploration of outer space and celestial bodies [36].

- The Common Heritage of Mankind (CHM) concept (Art I para 1 OST, Art. $11 \mathrm{MOON}$ )

The purpose of this doctrine, which is not restricted only to space law, is the protection of certain areas of great importance outside national territory and ensuring their integrity for future generations. It is reflected the United Nations Convention on the Law of the Sea [37] and can also be found in the Preamble of the Antarctic Treaty [38] without being explicitly mentioned there. As with the province of mankind clause, the notion of CHM brings forward the particular status of outer space as a domain which should be open and preserved for all states and generations.

- Military uses of outer space

Another important limitation to the freedoms of outer space is contained in Art. IV of the OST. Certain military uses of outer space, such as the placement of nuclear weapons and weapons of mass destruction in orbit around the Earth, their installment as well as the establishment of military bases and the testing of weapons on celestial bodies or their stationing anywhere in space, are prohibited. Furthermore, para 2, Art. IV provides that outer space may be used for "peaceful purposes only". While the exact meaning of the term "peaceful purposes" is contested, the leading opinion interprets it as non-aggressive, meaning that some military activities are acceptable if exercised lawfully (e.g., the right to self-defence, Art. 51 UN Charter) [39]. This provision is relevant especially as e.g., anti-satellite testing and other military destructive activities can produce a considerable amount of debris. 
- The environmental protection of outer space

A further limitation is contained in Art. IX of the OST, which is considered the basis for the environmental protection of outer space. By providing that states parties "shall conduct all their activities in outer space, including the Moon and other celestial bodies, with due regard to the corresponding interests of all other states" [40], this provision reaffirms the common character of outer space. Furthermore, it provides that the "harmful contamination" of outer space and celestial bodies shall be avoided (Art. IX sent. 2 OST) and, in case activities can potentially cause "harmful interference with activities of other states parties", consultations should be undertaken before the activity is carried out or continued (Art. IX sent. 3 and 4 OST).

Although the concepts used in Art. IX are difficult to define, it expresses the idea that there shall be protection of space activities from all forms of interference that might cause harm or pose a risk of harm to other states [40]. Thereby, Art. IX of the OST contains the principle of co-operation (Art. IX sent. 1 OST) which is also found in Articles III and X of the OST and was further developed in the other four treaties on space law. However, no specific requirements for states as to how to exercise their activities in a manner that would ensure that the standard of care towards of activities of other states are provided. Thus, the legal framework provides for some general direction for co-operation between the users of outer space but concrete instruments on how to ensure sustainability need to be formulated in more detail.

In fact, the treaties on space law neither expressly prohibit the creation of space debris nor impose an obligation on states and their space actors to remove space objects from orbit. Mitigation measures have so far only been adopted as voluntary, non-binding instruments and have been partly adopted in the national laws of some states [25].

In sum, it can be stated that a general obligation to protect the environment of outer space results from the common interest of the community of states to access and use outer space. If a narrow interpretation of the theory of erga omnes obligations is followed, it is the currently 107 State parties to the OST [32] which represent the community having a common interest in the protection of the usability of outer space. If the view is followed, that due to the broad support and the principle-based character of some of its norms, the Outer Space Treaty has at least partly customary character, it can be argued that the 107 State Parties represent the global community so that the global community has a legal interest in the environmental protection of outer space., but a concrete, binding way of action for SDR cannot be derived from existing space law [41].

\subsection{The Future of the Outer Space Environment}

\subsubsection{Sustainability as a Condition for the Usability of Outer Space}

What, then, can be done? In the context of the work of the United Nations Committee on the Peaceful Uses of Outer Space (UNCOPUOS), the sustainability of outer space is defined by the stability and safety of its environment which shall be "open for exploration, use and international cooperation by current and future generations ( . . )" [42], based on non-discrimination. Thus, sustainability is a condition for any future access to and use of outer space.

On the technical level, both mitigation and remediation concepts have been developed in order to facilitate the protection of near-Earth space from space debris aiming to "maintain the conduct of space activities indefinitely in the future" [43].

Out of the factors playing a role in the creation and distribution of space debris (orbit dynamics, air-drag on the residual atmosphere, on-orbit explosions, collisions, surface degradation slag from solid rocket motor firings, launch rates of future missions, operational practices and mitigation practices) a few will be tackled here that are the direct result of man-made activities.

In the style of the "leave no trace" paradigm of sustainable outdoor activities in nature here on Earth, several guidelines have been formulated as well for space activities; for instance, guidelines for the disposal of defunct satellites which are to be removed from LEO within 25 years after their 
end-of-life. In practice, this typically is realized by a final orbit maneuver which lowers the perigee as much as possible to ensure it will re-enter within 25 years. Such an action at the end of a mission is also beneficial with respect to another paradigm, which calls for a minimum impact on the environment. In a last orbit maneuver, all the leftover fuel can be used, which is one element of the passivation of satellites at their end-of-life. In general, passivation covers all forms of stored energy on board, let it be kinetics of the gyros, charge of batteries, and also fuel in the tanks. Passivation aims at the minimization of self-induced break-ups and it is expected that the number of explosions can be controlled very well by proper passivation and their severity can be significantly reduced (because e.g., the residual fuel cannot self-ignite when the tank corrodes and lead to a complete destruction).

That said, post-mission disposal considerations are to be seen in opposition to the space mission operators' desire to extend the nominal mission operation. Naturally, this is also a sustainable approach. It is usually better in terms of global sustainability to continue using old equipment (and accepting additional maintenance to a certain economic level) instead of throwing it away and replacing it. In space, however, maintenance is not easily done. Therefore, the risk of a critical failure on-board a satellite increases towards longer mission durations. From the sustainability point of view, it remains unclear when it is best to simply extend a mission and accept the higher risk of losing control over the satellite and not being able to perform disposal at all or to terminate the mission with a proper disposal maneuver and passivation.

The aforementioned example highlights that, as in other domains, there is a usually a conflict of interest between the immediate needs of spacecraft operators and the higher good of preserving the space environment in accordance with the treaties on space law. Space mission designers will always assess the collision probability due to space debris and define a tolerated risk threshold for their assets. In case the desired target orbit is already too densely populated with debris, it is possible to re-design and move to other, higher orbits. What is yet to be done is to strike an agreement at a global level to define acceptable inflictions on the space environment that are tolerable. An analogy can be drawn to the consensus on the two-degree goal in climate change. Maybe it is possible to discuss and formulate similarly memorable and easily understandable goals for the outer space environment. Although it is unlikely that the final sentence will state "Two collisions per year are tolerable", such goals would provide the necessary foundation for further action.

\subsubsection{The Need to Act}

As any significant accident in outer space leads to irreparable damage in orbital stability, it is not enough to mitigate the production of new space debris. In particular, the fact that in higher altitudes objects may remain over hundreds or even thousands of years, means that a potentially catastrophic effect for functional objects remains. Mitigation can indeed contribute to stabilizing the outer space environment, but further measures are necessary. For example, in LEO mitigation measures can only slow down the pace of growth but are not enough to stop it. Therefore, further measures aiming at reducing the existing space debris population through remediation are needed if the most used orbits are to remain usable. For example, a long-term scenario with five ADR missions per year clearly shows that remediation for large objects would lower the number of collisions in densely populated orbital regions from 10 to 5 and is, thus, advantageous [23].

While it has been estimated that the (isolated) application of SDR measures will not lead to a rapid change in the negative trends, there could be an apparent benefit to operational space objects in the long-term if ADR is performed in conjunction with space debris mitigation [44].

\section{The Definition and Scope of Space Debris Remediation}

Remediation mainly aims at removing existing pieces of orbital debris through active debris removal (ADR). Active debris removal involves the removal of intact but non-functional and/or uncontrolled objects (i.e., defunct satellites and rocket bodies). Moreover, these efforts could be supplemented by so-called on-orbit servicing of satellites (OOS). OOS aims at ameliorating the 
capabilities of satellites on orbit which have become non-functional through refueling and upgrading in order, first, to diminish the break-up risks and thus the creation of space debris, and second, to extend the satellite's life. As such measures relate to existing space objects, OOS can be considered partly a mitigation measure [45]. On-orbit servicing might also develop into repurposing or scavenging of valuable components from defunct satellites. Such concepts are currently being investigated by DARPA's Phoenix program [46,47], and certainly need to overcome challenges in automation and robotics in space operations and would benefit from standard interface ports for docking and modular designs [48].

Unlike mitigation measures, which aim at reducing the number of objects to be launched in orbit in the future, space debris remediation is designed to act against the consequences of orbital congestion with debris and aims at removing objects that are not functional anymore and thus represent a risk to space activities. So far, space debris remediation measures have been proposed but not yet applied in practice.

The effectiveness of the different disposal methods depends strongly on the type, mass and orbital position of the satellite. Such concepts for the removal objects from orbits include tethering, tugging, beaming with an electrostatic tractor (for GEO) [49], ion-beaming through relocation and lasering, net capturing [50], docking with a nozzle (especially in GEO), harpooning, de-orbiting with a drag augmentation sail, and de-orbit kits [51]. There are, however, also passive debris removal concepts. They involve the pre-launch instalment of systems such as drag augmentation devices which can deploy sails to accelerate the natural decay of satellites [52]; electrodynamic tethers [53,54] for de-orbiting, and thrust propulsion systems enabling de- or re-orbiting.

Moreover, the concept of laser debris removal foresees installing plasma jets on objects in order to enable controlled re-entry [55-57].

The focus of proposed remediation measures lies within the removal of larger objects and not of small objects as they act as triggers for the cascading effect. This has been shown through the results of the 2007 Fengyun 1C anti-satellite test by China in 2007 which "was adding more than 3300 trackable objects to the US Space Surveillance Network catalogue, increasing its size by $25 \%$ in just one incident" [58,59].

\subsection{The Deficiencies of the Legal Framework Related to Space Debris Remediation (SDR)}

While it is expected that the necessary advanced technology for SDR will become available in the foreseeable future, there are various legal problems that might challenge its practical implementation. The existing treaty law provides some main legal principles which set the legal framework for human activities in outer space. However, instruments for the protection of the space environment from space debris are not specifically provided for. Neither is space debris defined or its production prohibited, nor are the mitigation and remediation of space debris considered in the binding law. Thus, the creation and the non-removal of space debris is not recognized to be an unlawful act.

The following deficiencies of law with relation to SDR must be highlighted:

- It is not yet clear how a substantial risk should be defined so as to decide which fragments should be removed first. Art. II and III of the Registration Convention provide that space objects have to be registered in a national register and be carried on a register maintained by the United Nations General Secretary. Art. IV requires that data describing the name of the launching state(s), the designator of the space object, the date and territory of launch, the general function of the space object, as well as basic orbital parameters of the space objects (nodal period, inclination, apogee and perigee) are provided. However, these elements do not provide for the functionality and current status of the space object and, thus, cannot serve as criteria to determine its eligibility for removal.

- The legal framework does not provide standards to decide on whether an object constitutes space debris. Moreover, the legal regime for space activities does not define what space debris is. Therefore, it could be questionable what the criteria to define a space object as debris should be: 
its functionality, its controllability? For example, it could be aimed at first removing objects which cannot be attributed to a state registry-e.g., because their origin cannot be identified, which would be the case for the majority of small debris fragments.

- The question of attribution through registration is closely linked to the jurisdiction of states over their space objects. While outer space and celestial bodies are free from sovereignty, according to Art. VIII of the OST states shall retain jurisdiction and control over the space objects carried on their registry. The notion "jurisdiction" means that states withhold the power to legally enforce over their space objects and "control" is the factual element which ensures that the possibility to technically control the satellite lies within the state registry.

As a consequence, registered space objects can only be subjected to SDR by the state registry itself or with its permission.

Another relevant question is how to gain authorization to remove in cases where, for example, the state or registry neither consents to undertake the removal not does it provide authorization to a third party due to security concerns. As there is no legal obligation for states to remove their objects, this seems to be one of the most significant obstacles for SDR.

Another case to be addressed is if the state registry is unknown, e.g., because the space object has not been registered or the state registry is not identifiable. Could a state of necessity be applicable in urgent cases so that the removal, even without permission, remain lawful?

Self-help in a state of necessity $[60,61]$ could be invoked to justify measures aiming at "cleaning-up" the environment of outer space if the conditions for such justification are given [62], e.g., in order to safeguard an essential interest from a "grave and imminent peril". Interests not only of single states, but also of the international community as a whole have been recognized by the International Law Commission (ILC) as a ground to invoke necessity. The International Court of Justice, in the Gabčíkovo-Nagymaros Project Case [63], observed that self-help in a state of necessity as a ground for precluding wrongfulness can only be accepted under strictly defined exceptional conditions. Such conditions could, in the context of global common interests in the protection and sustainability of outer space, be an imminent threat to the space environment in order to preserve its usability. Therefore, provided that the growth in the number of activities will most probably induce the occurrence of accidents in outer space, it is conceivable that the concept of a state of necessity might gain relevance in the future and play a role in establishing legal rules for SDR.

- Also, the specific liability regime for space activities as established by Art. VII of the OST [26] and further elaborated in the 1972 Liability Convention [28] poses many questions for SDR operations. First, only states can be held liable for damages caused by space objects (Art. VII OST). Liability is, thereby, twofold: according to Art. II of the Liability Convention, for damages occurred in airspace or on the surface of the Earth, states have to pay compensation on the basis of "absolute liability". Therefore, no fault must be proven. The conditions that need to be given are a damage to property, life or health caused by a space object of a launching state to persons or states. (Art. I lit. (a) Liability Convention). Thus, attributability suffices, as long as it is known which the launching state is.

For damages in outer space, liability is fault-based (Art. III Liability Convention). Therefore, besides attributability, the fault of the launching state-thus the non-observation of a certain legal duty of care-also needs to be proven. This means that if a private entity undertakes an ADR operation and damage is caused to the space object of a third party, the liability is attributed to the launching state(s) of the removed object and not to the third party conducting the operation, whereas in Art. I lit. (c) Liability Convention, a launching State' is defined as the State which launches or procures the launching of a space object, or a State from whose territory or facility an object is launched.

The costs incurred, thus, have to be carried by the launching state. However, for the regulation of SDR, it is questionable whether the standard for fault liability should be the same as for conducting a SDR operation. 
- Furthermore, no change or transfer of ownership of space objects is foreseen in the space law treaties. Art. VIII of the OST foresees that jurisdiction and control shall be retained by the state registry. None of the space law treaty provisions includes a regulation regarding a possible transfer of ownership and control over satellites. Thus, once a state has launched a space object, even if it has been thereafter sold to another entity or state, the original launching state remains liable for all potential damages caused by this space object. Any deviating clause must be concluded bilaterally between the launching state and the purchaser and it is only binding between these two parties. Thus, in the case of an accident that occurred during an ADR mission on a transferred satellite, the original launching state will be held liable for any potential damage, although it might have not had any control possibilities over the satellite. The launching state can then only hold recourse against the purchaser according to their bilateral agreement for the compensation paid to the damaged party.

In practice, only a few transfers have taken place: e.g., of AsiaSat-1, APSTAR-I and APSTAR-IA from the United Kingdom to China in 1997, and of MARCOPOLO 1/BSB-1A from a British company to a Swedish national in 1999 [64]. Nevertheless, with the vast development of the commercial space market and the financial viability of satellite purchases triggered by the new space market, the legal issues related to change of ownership will gain more importance.

- Another relevant concern of launching states and entities with regard to ADR and OOS missions is security, especially for military satellites. As satellite infrastructure is a strategic asset, it is questionable whether state registries which do not possess enough financial and technological capabilities to remove their objects by themselves would give consent to third parties to undertake SDR. Furthermore, ADR systems entail a capability which is not restricted only to space debris and they could be used, if such an intent is given, for the removal or diversion also of assets. This dual characteristic, both civil and military, makes ADR a sensitive capability and presents a hurdle to reaching agreement between states for its implementation in practice and to raise funding in cooperation for the development of ADR techniques.

\subsection{SDR and the Role of Non-Binding Instruments}

The lacunae in the binding law regarding effective mechanisms for the protection of the common right to use and explore the outer space environment from the negative consequences of man-made debris have not remained completely unaddressed by the international community.

The prevention and reaction against space debris have become a main topic on the agenda of UNCOPUOS, IADC and other organisations that have considered possible mechanisms to impose obligations on states for their non-functional objects. For example, the missing definition and clarification of the legal nature of space debris in the treaties on space law has been taken up by the 2007 UNCOPUOS Space Debris Mitigation Guidelines [65] which provide that space debris are: "all man-made objects, including fragments and elements thereof, in Earth orbit or re-entering the atmosphere, that are non-functional". Also, the Space Debris Working Group of ESA has proposed an approach to define space debris by dividing human-made space objects in two categories: (a) functional active satellites under control; and (b) space debris that includes deactivated satellites, rocket upper stages and/or parts thereof, paint flakes etc.

Thereby, space debris is characterized by the fact that it is man-made and does not serve any purpose. However, there is no agreement on whether space debris should be considered to be space objects, as per the definition of "space object" of Art. I lit. (d) of the Liability Convention and Art. I lit. (c) of the Registration Convention [29], which, as it only clarifies that "The term 'space object' includes component parts of a space object as well as its launch vehicle and parts thereof", is rather a circular definition.

The technical guidelines for space debris mitigation by the IADC, [22] an intergovernmental organisation consisting of 12 national space agencies and ESA [66], as well as the UNCOPUOS 
Guidelines on Space Debris Mitigation, are applicable to "mission planning and the operation of newly designed spacecraft and orbital stages and, if possible, to existing ones". Such measures include: (1) limiting the debris released during normal operations, (2) minimizing of the potential for break-up during operational phases, (3) limiting the probability of accidental collision in orbit, (4) avoidance of intentional destruction and other harmful activities, (5) minimizing potential for post-mission break-ups resulting from stored energy, and (6) limiting the long-term presence of spacecraft and launch vehicle orbital stages in the low-Earth orbit region after the end of their mission [22,65].

Further non-binding instruments concerning the protection of the outer space environment from space debris were developed in the 2004 European Code of Conduct for Space Activities [20] which is applicable to projects of European space agencies, projects conducted in Europe, as well as by European entities outside Europe and to all space systems and launch vehicles orbiting or intended for orbiting the Earth. The 2014 ESA Space Debris Mitigation Policy for Agency Projects [67] is applicable to the procurement of all ESA space systems and all operations under the responsibility of ESA.

Since 2010, in the framework of UNCOPUOS a specific working group has been dedicated to the long-term sustainability of outer space activities. The Working Group has been tasked with formulating guidelines aiming at the long-term sustainable use of outer space. Thereby, current practices, operating procedures, technical standards, and policies relevant to space sustainability are considered as the backdrop to the legal framework governing space activities. A set of "best practices" for long-term sustainability in outer space has been drafted $[68,69]$ and the proposed guidelines are in the process of being finalized [70,71].

These guidelines are voluntary and include measures for, among others, sharing information on space objects and orbital events; conjunction assessment during all orbital phases of controlled flight; practical approaches for pre-launch assessment of possible conjunctions of newly launched space objects with space objects already present in near-Earth space; safety and security concerns for terrestrial infrastructure; criteria and procedures for the preparation and conduct of space activities aimed at the active removal of space objects from orbit; procedures and requirements for the safe conduct of operations resulting in the destruction of in-orbit space objects; criteria and procedures for the active removal of space objects and for the intentional destruction of space objects, specifically as applied to non-registered objects; risks associated with the uncontrolled re-entry of space objects; and measures of precaution when using sources of laser beams passing through outer space [72].

Summarizing, the Space Debris Mitigation Guidelines and other related instruments for the protection of the outer space environment from space debris depict environmentally relevant technical measures for future missions.

As these instruments are not legally binding, they do not create rules of international law, the violation or non-observation of which would give rise to an international responsibility of states for creating or for not mitigating space debris. Thus, compliance with such measures is only of a voluntary nature and cannot be legally enforced. Another weakness of the mitigation guidelines, content-wise, is the fact that they do not impose very restrictive mitigation strategies, although the constant growth of space debris would require this. For example, it could be considered whether the 25 -year rule is up to date in the backdrop of expected mega-constellations and the obvious reluctance of the international community to come up with binding rules on space debris mitigation.

Nevertheless, these non-binding instruments do not fully lack relevance as they can serve as a model for the development of national space laws which impose concrete obligations for implementing mitigation measures on private space actors.

Moreover, these instruments can also be seen as an expression of the willingness of the international community to formulate, even if only on a voluntary basis, certain technical standards for space activities in order to prevent the creation of space debris. Thus, they may serve as a basis for the development of a legal framework for space debris remediation. 


\subsection{Legal Avenues to Facilitate SDR}

One legal avenue to incorporate SDR mechanisms in the existing legal framework could be through national legislation. The example of space debris mitigation instruments being included in the national authorization requirements for space operators could serve as a model also for SDR. Some states, such as Argentina, Chile, the Netherlands, Poland, Spain and Switzerland have confirmed their adherence to the UNCOPUOS Guidelines. There are also states, such as Australia, Germany and Japan which have not enacted national legislation, but have elaborated state policies or standards for space debris mitigation for their national space agencies [25].

Furthermore, SDR and OOS measures could be implemented nationally as part of authorization or licensing requirements. This has already been the case with the national adherence to space debris mitigation guidelines. Thus, certain conditions can be prescribed to operators in space legislation: the legal basis for prescribing such conditions is Art VI of the OST which gives a "mandate" to states to authorize activities while, according to Art. IX of the OST, taking into account the activities of other states in outer space as per Art. IX.

Furthermore, the internal regulations of space agencies and intergovernmental organizations (IGOs) such as ESA can contribute to the development and implementation of SDR. Similarly, the 2014 ESA Space Debris Mitigation Policy for Agency Projects [67] is applicable to the procurement of all ESA space systems and all operations under the responsibility of ESA. The 2004 European Code of Conduct for Space Activities [20] is applicable to projects of European space agencies, projects conducted in Europe as well as by European entities outside Europe, and to all space systems and launch vehicles orbiting or intended for orbiting the Earth.

Thus, this practice of applying mitigation guidelines for ESA projects can serve as an example of how to ensure accordance also to SDR and OOS mechanisms for European projects, even if they have not acquired a binding character.

\subsection{Further Issues to Be Addressed by the Law}

Apart from the challenges in the legal dimension of SDR, other aspects will also be defining the practicability of remediation. They include a solution to overcome the financial hurdle for SDR as well as finding an effective approach to consider the strategic, security and military aspects of on-orbit servicing and active debris removal. Thus, a suitable form of international cooperation and organizational framework will be required.

The findings of the International Congress on Space Debris Remediation included following practical conditions as necessary [44]:

- a "cost effective" technique;

- a proper legal and policy framework to protect the parties involved and to deal with "alternative use" concerns;

- available and willing targets for removal or customer for servicing;

- funding: for the time being, for establishing, testing and developing technologies and SDR techniques; in the future-for carrying out such operations;

- $\quad$ accurate tracking and necessary assistance during operations;

- capability to locate, approach, connect deorbit/servicing device, control orientation and to move the target object to desired destination;

- $\quad$ safety of the public on the ground, at sea, travelling by air and in space. 
As far as the prospects for developing economic incentives for debris removal are concerned, a solution of creating a global fund in which all operators should contribute on an equitable basis has been proposed. This approach has become a standard in other activities taking place in global commons-e.g., in the telecommunications sector using fibre optics in the high seas. The main benefit of such an approach is the distribution of financial load between multiple entities. The justification for such an approach is that outer space activities are, ex definitone, ultra-hazardous, and very costly so that a distribution of risk is more practicable and effective than imposing costs only on single entities.

Also, these challenges, although they might not be directly originating from the law, could be facilitated through adequate regulation.

\section{Conclusions}

Space debris is an urgent matter and an issue of global importance for space activities. While the conflict between the use and the protection of outer space which results in the current trends of exponential and non-reversible growth of space debris is a pressing problem, the legal response hitherto has not been not effective so as to offer binding rules for space debris mitigation and remediation. It is true that a solution to such a complex problem cannot evolve only on a regulatory basis and requires technical, financial and political approaches, which, if implemented together with an adequate legal framework, can resonate the dimensions of orbital space debris pollution. The urgency of the problem cannot be overestimated and the need for action is vital for the use of near-Earth space.

Experience with space debris mitigation shows that even though the law is often far behind technological development, non-binding policies and efforts can play a substantial role and, furthermore, serve as a basis for the creation of binding rules. This pattern is valid also for space debris remediation which has to be included in the legal framework for outer space activities. The challenges for remediation seem to be at least as numerous as for mitigation, but as time is pressing for ensuring that the sustainable use of outer space will not be irreversibly impeded, the development of adequate SDR mechanisms at an international and national level should not be postponed as they will be defining the future of the outer space environment and the viability of space activities.

Author Contributions: Rada Popova wrote the main sections of the paper and Volker Schaus provided data for Sections 2.1 and 2.3.1, and wrote the main part of Section 2.3.1.

Acknowledgments: Parts of this research on the legal aspects of space debris remediation have been made possible by the ReDSHIFT project which has received funding from the Horizon 2020 Program of the European Union's Framework Programme for Research and Innovation (H2020-PROTEC-2015) under REA grant agreement $\mathrm{n}^{\circ}$ [687500]-ReDSHIFT. So far, no funds have been received for covering the costs to publish in open access, but, in case the article gets accepted, open access fees could be financed through the budget provided by the ReDSHIFT project to the Institute of Air and Space Law at the University of Cologne.

Conflicts of Interest: The founding sponsors had no role in the design of the study; in the collection, analyses, or interpretation of data; in the writing of the manuscript, and in the decision to publish the results.

\section{References and Notes}

1. IADC. Stability of the Future LEO Environment, IADC-12-08, Rev. 1. Available online: https: / /www.iadc-online.org/Documents/IADC-2012-08,\%20Rev\%201,\%20Stability\%20of\%20Future\% 20LEO\%20Environment.pdf (accessed on 28 March 2018).

2. Space Launch Report: Orbital Launch Summary by Year. Available online: http://www.spacelaunchreport. com/logyear.html (accessed on 27 February 2018).

3. Union of Concerned Scientists Satellite Database. Available online: http://www.ucsusa.org/nuclearweapons/space-weapons/satellite-database\#.WhyVnVNrw2x (accessed on 23 February 2018).

4. Johnson, N.L.; Krisko, P.H.; Lion, J.-C.; Anz-Meador, P.D. NASA's New Breakup Model of EVOLVE 4.0. Adv. Space Res. 2001, 28, 1377-1384. [CrossRef]

5. European Space Agency. Space Situational Awareness. Available online: http://www.esa.int/Our Activities/Operations/Space_Situational_Awareness/Space_Surveillance_and_Tracking_-_SST_Segment (accessed on 23 February 2018). 
6. Kessler, D.J.; Cour-Palais, B.G. Collision Frequency of Artificial Satellites: The Creation of a Debris Belt. JGR 1978, 83, 2645. [CrossRef]

7. Eichler, P.; Rex, D. Chain Reaction of Debris Generation by Collision in Space-A Final Threat to Spaceflight? In Proceedings of the 40th Congress of the IAF, Malaga, Spain, 7-13 October 1989; Paper IAA-80-628, p. 3.

8. OneWeb. Available online: http://www.oneweb.world/ (accessed on 23 February 2018).

9. Small Satellites and Large Satellite Constellations. In Global Space Governance: An International Study; Jakhu, R., Pelton, J., Eds.; Springer: Cham, Switzerland, 2017; pp. 369-373. ISBN 978-3-319-54364-2.

10. IADC. Statement on Large Constellations of Satellites in Low Earth Orbit, (February 2016). Available online: http:/ / www.iadc-online.org/Documents/IADC-15-03\%20Megaconstellation\%20Statement.pdf (accessed on 23 February 2018).

11. FCC Grants Oneweb Access to U.S. Market for Broadband Satellite Constellation. 22 June 2017. Available online: https:/ / www.fcc.gov / document/fcc-grants-oneweb-us-access-broadband-satellite-constellation (accessed on 28 March 2018).

12. Ben Larbi, M.; Grzesik, B.; Radtke, J.; Trentlage, C.; Stoll, E. Active Debris Removal for Mega Constellations: CubeSat Possible? In Proceedings of the 9th International Workshop on Satellite Constellations and Formation Flying, Boulder, CO, USA, 19-21 June 2017.

13. USSTRATCOM Space Control and Space Surveillance. 17 October 2016. Available online: http:/ / www.stratcom.mil/Media/Factsheets/Factsheet-View/Article/976414/usstratcom-spacecontrol-and-space-surveillance/ (accessed on 23 February 2018).

14. Scanning and Observing. Available online: http://www.esa.int/Our_Activities/Operations/Space_Debris/ Scanning_and_observing (accessed on 23 February 2018).

15. Wiedemann, C.; Braun, V. The Necessity of Removing a Sun-synchronous Satellite. Paper DLRK 2014-340017. In Proceedings of the Deutscher Luft- und Raumfahrtkongress, Augsburg, Germany, 16-18 September 2014.

16. Leonov, V.A.; Bargov, A.V. Study of Space Debris Burning in Earth's Atmosphere via Television Meteor Monitoring. Astrophys. Bull. 2011, 66, 87-89. [CrossRef]

17. Horstmann, A. Technical note-MASTER-8: Enhancement of S/C fragmentation and environment, to be published.

18. Wiedemann, C.; Flegel, S.; Möckel, M.; Braun, V.; Krag, H.; Klinkrad, H.; Vörsmann, P. Flux Calculation Using Population Event Clouds. Paper IAC 11.A6.2.16. In Proceedings of the 62nd International Astronautical Congress, Cape Town, South Africa, 3-7 October 2011.

19. Krisko, P.H.; Flegel, S.; Matney, M.; Jarkey, D.; Braun, V. ORDEM 3.0 and MASTER-2009 modeled debris comparison. Acta Astronaut. 2015, 113, 204-211. [CrossRef]

20. European Code of Conduct for Space Activities, Issue 1.0. 31 June 2014. Available online: http:/ /www. unoosa.org/documents/pdf/spacelaw/sd/2004-B5-10.pdf (accessed on 23 February 2018).

21. European Space Agency. Annual Space Environment Report. Available online: https://www.sdo.esoc.esa. int/environment_report/Environment_Report_I1R2_20170427.pdf (accessed on 23 February 2018).

22. IADC. Space Debris Mitigation Guidelines, Rev. 1; IADC: Houston, TX, USA, 2007.

23. Schaus, V.; Radtke, J.; Stoll, E.; Rossi, A.; Colombo, C.; Tonetti, S.; Holbrough, I. Results of reference long-term simulations focussing on passive means to reduce the impact of space debris. In Proceedings of the 7th European Conference on Space Debris, Darmstadt, Germany, 18-21 April 2017.

24. Findings as per the Report on Review of the State-of-the-Art and Reference Simulations Results in the ReDSHIFT Project. 12 April 2017; p. 82.

25. UNCOPUOS. Compendium on Space Debris Mitigation Standards Adopted by States and International Organizations; UN Doc. A/AC.105/C.2/2016/CRP.16; UNCOPUOS: Vienna, Austria, 2016.

26. Treaty on Principles Governing the Activities of States in the Exploration and Use of Outer Space, Including the Moon and Other Celestial Bodies; 610 UNTS 205; entered into force on 10 October 1967.

27. Agreement on the Rescue of Astronauts, the Return of Astronauts and the Return of Objects Launched into Outer Space; 672 UNTS 119; entered into force 3 December 1968.

28. Convention on International Liability for Damage Caused by Space Objects; 961 UNTS 187; entered into force 1 September 1972.

29. Convention on Registration of Objects Launched into Outer Space; 1023 UNTS 15; entered into force 15 September 1976. 
30. Agreement Governing the Activities of States on the Moon and Other Celestial Bodies; 1363 UNTS 13; entered into force 11 July 1984.

31. Hobe, S. Outer Space as the Province of All Mankind-An Assessment of 40 years of Development. In Proceedings of the 50th Colloquium on the Law of Outer Space, Hyderabad, India, 24-29 September 2007; p. 442.

32. Status of International Agreements Relating to Activities in Outer Space. Available online: http:/ / www. unoosa.org/oosa/en/ourwork/spacelaw/treaties/status/index.html (accessed on 23 February 2018).

33. Brownlie, I. Principles of Public International Law, 6th ed.; Diakonia: Bromma, Sweden, 2003; pp. 6-12. ISBN 978-0199260713.

34. Jakhu, R. Legal issues relating to the global public interest in outer space. J. Space Law 2006, 32, 31-110.

35. Hobe, S. Outer Space Treaty. In Commentary on Space Law; Schmidt-Tedd, H., Schrogl, K.-U., Eds.; Heymanns Verlag: Cologne, Germany, 2009; Volume 1, p. 35. ISBN 978-3-452-27185-3.

36. Hobe, S.; Tronchetti, F. Article 4 (Province of All Mankind). In Commentary on Space Law; Schmidt-Tedd, H., Schrogl, K.-U., Eds.; Heymanns Verlag: Cologne, Germany, 2013; Volume 2, pp. 364-366. ISBN 978-3-452-27523-3.

37. United Nations Convention on the Law of the Sea; 1833 UNTS 3; entered into force on 10 December 1982.

38. Antarctic Treaty; 402 UNTS 71; entered into force on 23 June 1961.

39. Schrogl, K.-U.; Neumann, J. Article IV OST. In Cologne Commentary on Space Law; Schmidt-Tedd, H., Schrogl, K.-U., Eds.; Heymanns Verlag: Cologne, Germany, 2009; Volume 1, p. 90. ISBN 978-3-452-27185-3.

40. Marchisio, S. Article IX. In Cologne Commentary on Space Law; Schmidt-Tedd, H., Schrogl, K.-U., Eds.; Heymanns Verlag: Cologne, Germany, 2009; Volume 1, pp. 175-177. ISBN 978-3-452-27185-3.

41. Wolfrum, R. Die Internationalisierung Staatsfreier Räume; Springer: Berlin/Heidelberg, Germany; New York, NY, USA, 1983; p. 262. ISBN 978-3-642-69481-3.

42. UNCOPUOS. Guidelines for the Long-Term Sustainability of Outer Space Activities, Working Paper by the Chair of the Working Group on the Long-Term Sustainability of Outer Space Activities; U.N. Doc. A/AC.105/2017/CRP.26; 14 June 2017. Available online: http://www.unoosa.org/res/oosadoc/data/documents/2017/aac_ 1052017crp/aac_1052017crp_26_0_html/AC105_2017CRP26E.pdf (accessed on 23 February 2018).

43. UNCOPUOS. Working Group on the Long-Term Sustainability of Outer Space Activities: Preambular Text and Nine Guidelines, Conference Room Paper by the Chair of the Working Group on the Long-Term Sustainability of Outer Space Activities; U.N. Doc. A/AC.105/C.1/2018/CRP.18; 7 February 2018. Available online: http://www.unoosa.org/res/oosadoc/data/documents/2018/aac_105c_12018crp/aac_ 105c_12018crp_18_0_html/AC105_C1_2018_CRP18E.pdf (accessed on 23 February 2018).

44. UNCOPUOS. Active Debris Removal-An Essential Mechanism for Ensuring the Safety and Sustainability of Outer Space A Report of the International Interdisciplinary Congress on Space Debris Remediation and On-Orbit Satellite Servicing; UN Doc. A/AC.105/C.1/2012/CRP.16; 27 January 2012. Available online: http:/ /www.unoosa. org/pdf/limited/c1/AC105_C1_2012_CRP16E.pdf (accessed on 23 February 2018).

45. NASA. On-Orbit Satellite Servicing Study Project Report; NASA: Washington, DC, USA, 2010; p. 35. Available online: https://sspd.gsfc.nasa.gov/images/nasa_satellite\%20servicing_project_report_0511.pdf (accessed on 23 February 2018).

46. Space Safety Magazine. DARPA's PHOENIX: Scavenging Defunct GEO Satellites. Available online: http:/ / www.spacesafetymagazine.com/press-release/darpas-phoenix-scavenging-defunct-geosatellites / (accessed on 28 March 2018).

47. DARPA. Robotic Servicing of Geosynchronous Satellites (RSGS). Available online: https://www.darpa.mil/ program/robotic-servicing-of-geosynchronous-satellites (accessed on 27 March 2018).

48. Melroy, P.; Hill, L.; Fowler, E.E.; Hunter, R.; Eagen, J.; Sullivan, B.R.; Will, P.; Palmer, J. DARPA Phoenix Satlets: Progress towards Satellite Cellularization. In Proceedings of the AIAA SPACE 2015 Conference and Exposition, Pasadena, CA, USA, 31 August-2 September 2015.

49. Hogan, E.A. Electrostatic Tractor Analysis for GEO Debris Remediation, Aerospace Engineering Sciences Graduate Theses and Dissertations; Paper 4; University of Colorado Boulder: Boulder, CO, USA, 2014; p. 4.

50. Biesbroek, R. ESA's e.deorbit mission and its roadmap to Active Debris Removal. In Proceedings of the 5th CEAS Air \& Space Conference, Delft, The Netherlands, 7-11 September 2015. 
51. Macdonald, M.; McInnes, C.; Bewick, C.; Visagie, L.; Lappas, V.; Erb, S. Concept-of-operations disposal analysis of spacecraft by gossamer structure. J. Spacecr. Rockets 2015, 52, 517-525. [CrossRef]

52. Lappas, V.; Adeli, N.; Visagie, L.; Fernandez, J.; Theodorou, T.; Steyn, W.; Perren, M. CubeSail: A low cost CubeSat based solar sail demonstration mission. Adv. Space Res. 2011, 48, 1890-1901. [CrossRef]

53. Tethers Unlimited Website. Available online: https://www.tethers.com (accessed on 28 March 2018).

54. Ohkawa, Y.; Kawamoto, S.; Okumura, T.; Iki, K.; Horikawa, Y.; Kawashima, K.; Miura, Y.; Takai, M.; Washiya, M.; Kawasaki, O.; et al. Preparation for on-orbit demonstration of electrodynamic tether on htv. In Proceedings of the Joint Conference of 30th International Symposium on Space Technology and Science, 34th International Electric Propulsion Conference and 6th Nano-Satellite Symposium, Hyogo-Kobe, Japan, 4-10 July 2015.

55. NASA. Project ORION: Orbital Debris Removal Using Ground/Based Sensors and Lasers; NASA Technical Memorandum 108522; NASA: Washington, DC, USA, 1996.

56. Phipps, C.R. L'ADROIT-A Spaceborne Ultraviolet Laser System for Space Debris Cleaning. Acta Astronaut. 2014, 104, 243-255. [CrossRef]

57. Scharring, S.; Wilken, J.; Eckel, H.-A. Laser-based removal or irregularly shaped space debris. Opt. Eng. 2016, 56, 011007. [CrossRef]

58. ESA. Frequently Asked Questions. Available online: http://www.esa.int/Our_Activities/Operations/ Space_Debris/FAQ_Frequently_asked_questions (accessed on 28 February 2018).

59. Dolado-Perez, J.; Pardini, C.; Anselmo, L. Review of Uncertainty Sources Affecting the Long-term Predictions of Space Debris Evolutionary Models. Acta Astronaut. 2015, 113, 51-65. [CrossRef]

60. ILC. Articles on State Responsibility for Internationally Wrongful Acts; Article 25; UNGA Res. 56/83 of 12 December 2001.

61. Fitzmaurice, M. Necessity in International Environmental Law. In Netherlands Yearbook of International Law; Dekker, I.F., Hey, E., Eds.; Springer: Berlin/Heidelberg, Germany; New York, NY, USA, 2010; Volume 41, ISBN 9789067047364.

62. Legal Issues and Policy Concerns under the Current Framework for On-Orbit Servicing and Active Debris Removal. In Global Space Governance: An International Study; Jakhu, R., Pelton, J., Eds.; Springer: Berlin/Heidelberg, Germany; New York, NY, USA, 2017; p. 345. ISBN 978-3-319-54363-5.

63. Gabčíkovo-Nagymaros Project (Hungary v Slovakia), Judgment, I.C.J. Reports 1997, p. 7.

64. Jakhu, R.; Nyampong, Y.; Sgobba, T. Regulatory framework and organization for space debris removal and on orbit servicing of satellites. J. Space Saf. Eng. 2017, 4, 131. [CrossRef]

65. Space Debris Mitigation Guidelines of the Committee on the Peaceful Uses of Outer Space; UNGA Res. 62/217 of 22 December 2007.

66. IADC. Inter-Agency Space Debris Coordination Committee. Available online: http://www.iadc-online.org/ (accessed on 23 February 2018).

67. Space Debris Mitigation Policy for Agency Projects. ESA/ADMIN/IPOL (2014)2 of 28 March 2014. Available online: http:/ / www.iadc-online.org/References/Docu/admin-ipol-2014-002e.pdf (accessed on 23 February 2018).

68. UNCOPUOS. Report of the Committee on the Peaceful Uses of Outer Space Fifty-Fourth Session, pp. 51-57, Annex II. Terms of Reference and Methods of Work of the Working Group on Long-Term Sustainability of Outer Space Activities of the Scientific and Technical Subcommittee; U.N. Doc. A/66/20 (2011). Available online: http:/ / www.unoosa.org/pdf/gadocs/A_66_20E.pdf (accessed on 23 February 2018).

69. UNCOPUOS. Report of the Committee on the Peaceful Uses of Outer Space Fifty-Seventh Session; U.N. Doc. A/69/20 (2014). Available online: http://www.unoosa.org/pdf/gadocs/A_69_20E.pdf (accessed on 23 February 2018).

70. UNCOPUOS. Proposal by the Chair of the Working Group on the Long-Term Sustainability of Outer Space Activities for the Consolidation of the Set of Draft Guidelines on the Long-Term Sustainability of Outer Space Activities; U.N. Doc. A/AC.105/2014/CRP.5. Available online: http://www.unoosa.org/pdf/limited/1/AC105_2014_ CRP05E.pdf (accessed on 23 February 2018). 
71. UNCOPUOS. Draft Report of the Committee on the Peaceful Uses of Outer Space Fifty-Ninth Session, Addendum One 118; U.N. Doc. A/AC.105/L.309/Add.1; 2017. Available online: http://www.unoosa.org/res/ oosadoc/data/documents/2017/aac_1051/aac_1051_309add_1_0_html/AC105_L309Add01E.pdf (accessed on 23 February 2018).

72. UNCOPUOS. Guidelines for the Long-Term Sustainability of Outer Space Activities, Proposal by the Chair of the Working Group on the Long-Term Sustainability of Outer Space Activities; U.N. Doc. A/AC.105/2017/CRP.23;

2 June 2017. Available online: http://www.unoosa.org/res/oosadoc/data/documents/2017/aac_ 1052017crp/aac_1052017crp_23_0_html/AC105_2017CRP23E.pdf (accessed on 23 February 2018). 